\title{
So, what is asset management anyway?
}

\author{
Perry Weinstein \\ is North American Sales Manager, Media Asset Management, for Harris Corporation. Having learned from hard-earned experience, he \\ believes asset management is first and foremost a business solution (as opposed to a technical one) and an enabler in implementing \\ effective business plans.
}

\section{Keywords: digital, content, media asset management, MAM, workflow}

Abstract What is asset management? Is it a proven money saver? Does it offer expansion to the broadcast and media industries with only marginally increased overheads? This new technology has been the subject of excited talk for some time but, with numerous asset management systems available, the marketplace has been left in some confusion as to what it has to offer them. This paper provides a detailed look into the qualities and advantages of asset management. It maintains that media asset management (MAM) takes broadcasters a step beyond anything they have been able to do before. By utilising MAM, broadcast and media outlets can realise inter- and cross-departmental process improvement. This results in a lower cost of doing business or this extra media handling capacity can be applied to produce new revenue streams. At this time the broadcast industry is not especially receptive to sales pitches calling for new capital investment. Global business conditions have slowed capital investment in new equipment regardless of inherent value. Therefore, even before new technologies are evaluated, there are fundamental questions: does it help the business or save money? This paper aims to answer these questions based on the notion that asset management is, first and foremost a business decision.

\section{SO, WHAT IS ASSET MANAGEMENT ANYWAY?}

The industry has been talking excitedly about media asset management for a while, but there is a lot of confusion among broadcasters fueled by messages from suppliers, and marketing hyperbole. As an industry saddled with more acronyms than actual words, the launch of asset management technologies has further muddied the water. Many convoluted descriptions intended to brand this solution set proliferate; for example, descriptors include: digital asset management (DAM), media asset management (MAM), video content management (VCM), or digital content management (DCM) - to name just a few. The net result is a marketplace having to invest valuable time in the quest to understand exactly what asset management is or can offer it.

Standardizing on intuitive terminology would help resolve some of these issues. This, though, may be an unattainable goal, since asset management is inherently hard to define.

The industry agrees on the fundamental "what" of asset management, which includes a variety of functionalities enabling broadcasters to:

- ingest, catalog, and store media digitally by metadata values

- research and edit metadata for better indexing of media content

- browse and select media for retrieval

- trim, time, and edit media, and

- transfer the media where and when it's needed.

Put simply, MAM takes broadcasters a step beyond anything they have been able to do before. All departments in a broadcast facility will have access to programming, commercials, and playlists at their fingertips. They will be able to accelerate the production process; repurpose content more quickly, easily and cheaply; react 
faster to things such as commercial changes, and be able to pull up information for content providers and advertisers in an instant.

Asset management is not a single product but rather a collection of wide-ranging applications that, when fully integrated, become an interconnected system to manage media and content. Most offerings include a collection of 5-15 different products comprising a total solution - not including integration to legacy systems. Therefore, it stands to reason that the terminology will remain broad and allencompassing.

\section{IN THE END, IT'S ALL ABOUT BUSINESS}

At this time, the broadcast industry is not especially receptive to sales pitches calling for new capital investment. Global business conditions have slowed capital investments in new equipment, regardless of inherent value. Therefore, even before new technologies are evaluated, there is a fundamental question asked: does it help the business make or save money? We all have something very basic in common - the need for our respective businesses to make a profit. Customers, therefore, begin meetings with one of the following two questions:

- How can asset management help me lower my cost of doing business?

- How can asset management expand my business without increasing or only marginally increasing my overhead?

We've learned that these business goals and return on investment (ROI) are achievable with asset management systems. But, how each solution has achieved these goals is different.

Describing the how in regards to the why seems to have stumped the industry - and rightly so. The features and functionality, let alone the technologies utilized, vary widely.

This is to be expected in the first phase of adoption in any new market. In any technology transition, the first installations are large, complex, customized projects for customers interested in a completely new solution. The projects have had large scopes, bigger budgets, and many revisions to finally provide a working solution. These pioneers are early innovators who are not risk averse to new methods of working or achieving business results; inevitably they have built a solid set of best practices from hard lessons learned.

Based on these lessons, vendors such as Harris have been able to develop offerings proclaiming stable, standardized, and modular platforms solutions. According to Kane Consulting, ${ }^{1}$ a European-based DAM consulting and research firm, this provided the momentum for the industry to move into the second phase of implementation in 2004. Before then, products were more prototypes and experiments. Now, they are market and field-proven solutions for the broadcast and rich media industries.

\section{EMERGING MODELS}

As this new phase of industry adoption has evolved, certain market segments are at the forefront. Based on Harris's experience, as well as Kane's industry analysis, three key models within the broadcast industry have surfaced as the most active segments in this phase of implementation: playout, news production, and archival management and distribution. The value proposition stays the same, but the feature sets vary based on the broadcast environments implementing asset management systems.

The most common of these three are playout centers - distribution and transmission operations requiring the right media in the right format at the right time. To accomplish this, a focused set of functionality is required. First, playout centers require the ability to ingest media digitally as well as manage these media through efficient storage, archival, tracking, and retrieval processes. All media must be managed in a format independent environment, across multiple platforms and automatically delivered on time to the proper destination. Therefore, systems have been optimized for real-time intelligent management and distribution of media; for this broadcaster, it is all about creating a more efficient up-front process within the operational environment. This provides a strategic competitive advantage through speed and reduced costs in the facility. The cost savings can be pocketed or used to fund new programming streams or services without additional costs.

Intelligent management of media cannot be 
limited to the playout center's technical core. Desktop access provides content and media throughout the facility, enabling more efficient cross-departmental communication. In the past, staff members had to physically go to the technical center or request a costly dub, just to view media. With asset management systems, previews of such material can be readily accessed throughout the enterprise, thereby improving collaboration, decision making, and decreasing overhead.

For most broadcasters, the stakes are usually higher within a news production department; therefore, asset management solutions provide immediate benefits. A major industry trend accelerating adoption is the proliferation of server-based editing in newsroom environments. As broadcasters have transitioned to all-digital news facilities, the storage of news assets has quickly led to the question: now, how do we store these for long-term use? The logical next step is implementing a solution providing easy access and retrieval of media.

Asset management provides functionality reducing the time required to develop and produce quality news content, directly impacting a broadcaster's bottom line. Such solutions must efficiently log incoming news feeds, including live and/or automated indexing of this material. Accessibility of new media at the point of best use is critical, as more and more journalists are responsible for editing final product. Therefore, being able to view and make editorial decisions at any point in the collaborative process directly impacts the quality of the product, cost of production, and time-toair. These benefits can improve competitive advantage, and result in an increase in viewership. Any incremental increase in news ratings generally results in substantial returns to the bottom line.

Of course, the ability to file and find media later - called a deep archive — is essential to the success of both playout and news operations. It is assumed the asset management systems provide this as an integrated feature. What is interesting, though, is this functionality is emerging as a stand-alone offering.

Sports teams, governmental bodies, corporations, and educational institutions have consistently utilized rich media libraries. Sophisticated asset management tools simplify this highly manual process; currently, assets are hidden in deep archives, only accessible with a librarian's assistance. But, second generation asset management systems automate such workflows, creating a system that can be used by more than "expert" users. The net result is media can be quickly found and immediately repurposed, thus generating revenue, saving time, and decreasing user frustrations.

With any of the above models, the solutions require adaptability to unique business processes with standardized offerings. It is assumed customers will need some level of configurability in the asset management system; the chief enabler for this is workflow management tools. These standardized tools provide user-specific configurations for each individual operation; in other words, it is a custom solution without custom code that is both highly modular and supportable.

Workflow management tools supplement second generation asset management solutions. The bottom line is that normal operations are almost completely automated, and system exceptions notify highly skilled operators to manage potential problems versus routine tasks.

\section{THE MARKET IS READY}

Clearly we are now entering the era of second generation DAM systems. The pioneers of the first generation struggled with the proprietary databases, costly customized interfaces to legacy systems, and the disappointment of multimillion dollar investments failing to fully achieve their ambitious ROI targets. We owe a debt of gratitude to these early adopters but more importantly we must learn from the past and avoid the pitfalls of those large and overly ambitious investments.

The next generations of systems designed for targeted applications with a clearly achievable ROI are now available. Risks are significantly lowered by employing best practice models and using modular components that can be easily modified or replaced. Systems interfaces based on the business-to-business technology developed in the dot.com era make it possible to design DAM systems that integrate best-in-class products from multiple vendors. Additionally, standardized data models have emerged. They 
ease the migration path where systems must be upgraded or expanded with new technologies.

There has never been a better time to deploy a DAM solution and start enjoying the clear productivity gains, increasing the value and profitability of your business.

\section{Reference}

1 Bebert, M. H. (2003) "DAM 2003 Benchmark Study on Digital Asset Management, 144 Cases in North America and Europe," Version 2, study published for TV channels and broadcasters. 